\title{
INFLUENCE OF NEW CONSTRUCTION PROJECTS ON VINOHRADY TUNNELS
}

\author{
JIŘÍ BARTÁK \\ Czech Technical University in Prague, Faculty of Civil Engineering, Depatment of Geotechnics, Thákurova 7, \\ 16629 Prague, Czech Republic \\ correspondence: bartakj@fsv.cvut.cz
}

\begin{abstract}
After demolition of the brutalist architectural style Transgas building in Vinohradská Street, Prague, (all buildings of which were located above the historic Vinohrady tunnels II and III), there will be built the Vinohradská Administration Centre with the addition of a building No. 345 called "Above the Museum". Both buildings have the foundation joint immediately above the lining of the existing tunnels. This paper describes the main phases of construction and the character and size of the deformation affecting the stone block lining of the tunnels.
\end{abstract}

KEYWORDs: Cracks, deformations, influence on tunnel lining, new buildings, Vinohrady tunnels.

\section{Brief History of Construction of VinOHRADY TUNNELS}

The Vinohrady tunnel I was brought into service in 1871 as a substantial part of the Franz Joseph I single track rail line leading from Vienna, through the Lower Austrian city of Gmünd, to Prague. The $1146 \mathrm{~m}$ long tunnel was built over a period of two years (1869 - 1871) using a classical Austrian tunnelling system, and in difficult conditions under the relatively dense development of the then Vinohrady district. It did not proceed without damaging a number of buildings and structures. Over the next twenty years, a number of defects (leaks, cracks) appeared on the tunnel lining. For that reason the reconstruction of the tunnel was already under consideration by about 1900 . The reconstruction did not actually take place until 1945-1948, when sandstone blocks in the lining vault were replaced by granite keystones and the external waterproofing of the vault was repaired.

Until the opening of Tunnel II in 1944, the southheading rail line was led through Tunnel I - via Vršovice, Tábor and Gmünd to Vienna. At present, the rail line leading west in the direction of Smíchov and Plzeň passes through Tunnel I. Crossing the state border with Germany is possible at several places.

The Vinohrady tunnel II was built in 1940-1944 concurrently with Tunnel I, again using a classical Austrian tunnelling system, with a length of $1149 \mathrm{~m}$. The upper vault of Tunnel II was carried out using trapezoidal high-quality granite blocks 1.0 to $1.3 \mathrm{~m}$ thick; the side walls were made of unreinforced concrete [1]. A $6 \mathrm{~m}$ wide and $290 \mathrm{~m}$ long intermediate abutment wall was built during the course of the Tunnel II construction between Tunnel II and a Tunnel III, reaching approximately up to Anglická Street. The abutment wall has a $2 \mathrm{~m}$ wide corridor in the middle, which is connected with Tunnel II and Tunnel III by transverse galleries, also $2 \mathrm{~m}$ wide (see Figure 1). Tunnel III was directed according to this design subsequently.

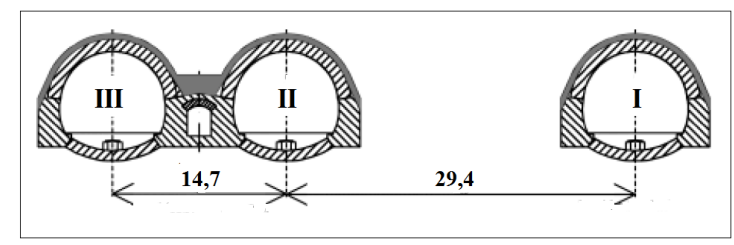

Figure 1. Vinohrady tunnels ([1] - modified $)$

At present the line from Prague heading south to České Budějovice runs through tunnel II, with a turnoff in Veselí nad Lužnicí, and heads in the same historic direction of České Velenice, Gmünd and Vienna.

The Vinohrady Tunnel III was built to the above-mentioned length of $290 \mathrm{~m}$ in the period from 1940 to 1944 . The handling tracks were placed into the incomplete double-track tunnel; the tunnel was additionally used as a wine cellar. The construction continued later, in 1983-1989, in connection with the expansion of the main railway station and the construction of the Prague-South rail storage yard. The original double-track tunnel was followed up with $722 \mathrm{~m}$ and $794 \mathrm{~m}$ long tunnels respectively, beginning in a bifurcation chamber, and carried out in a $30 \mathrm{~m}$ deep shaft in Anglická Street. The single-track tunnels were driven using the Ring Method, which was applied at that time even to the construction of the Prague Metro.

At present, the line heading south from Prague to České Budějovice, or in the historic direction of České Velenice, Gmünd and Vienna, is also led through the single-track tunnels of the Vinohrady Tunnel III. 


\section{Buildings in the Area of Low Tunnel Overburden}

\subsection{Characteristic of Old Buildings}

Old buildings along Vinohradská Avenue (1922-1939 Fochova Avenue, 1940-1945 Schwerinova Avenue, 19481969 Stalinova Avenue.) above the future Tunnels II and II were demolished by the Ministry of Posts and Telegraphs in 1939-1940, with the exception of building No. 343, "Above the Museum", under which the construction of Tunnel II was in preparation. The building was underpinned classically before the Tunnel II excavation, that is by reinforced concrete beams supporting the bearing walls of the structure. Shaft pillars forming the supports of the underpinning beams transferred loads induced by the building to the formation level of Tunnels II and II (see Figure 2).

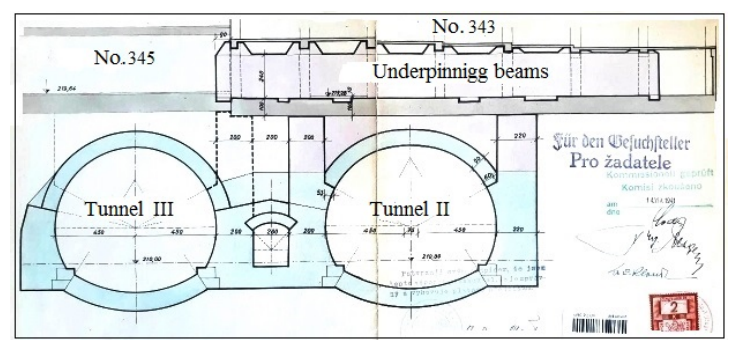

FiguRE 2. Diagram of underpinning the existing Above the Museum building No. 343 [1]

Four other houses on the corner of Římská and Rubešova Streets were demolished in 1965, so an extensive gap was created next to the CS Radio building, located also above Tunnel III.

In connection with the construction of the transit gas pipeline from the then USSR to the countries of Central Europe, this vacancy was used for the construction of a complex of Transgas buildings. The construction took place in 1972-1978. It was one of several other important buildings of the so-called brutalist architectural style. The most important part of the complex was the relatively low building of the transit gas pipeline control centre, which faced Vinohradská Avenue, and two large tower office buildings were built in the rear part of the vacant space (see Figure 3).

Deliberations on the demolition of the entire Transgas complex and the creation of a modern administration centre started in 2014. As the Ministry of Culture rejected the inclusion of this important category "A" building given status as a cultural monument, a new plan was instigated for implementation and, on 15 February 2019, the demolition began. Regarding the superstructure, it was practically completed in the spring of 2020.

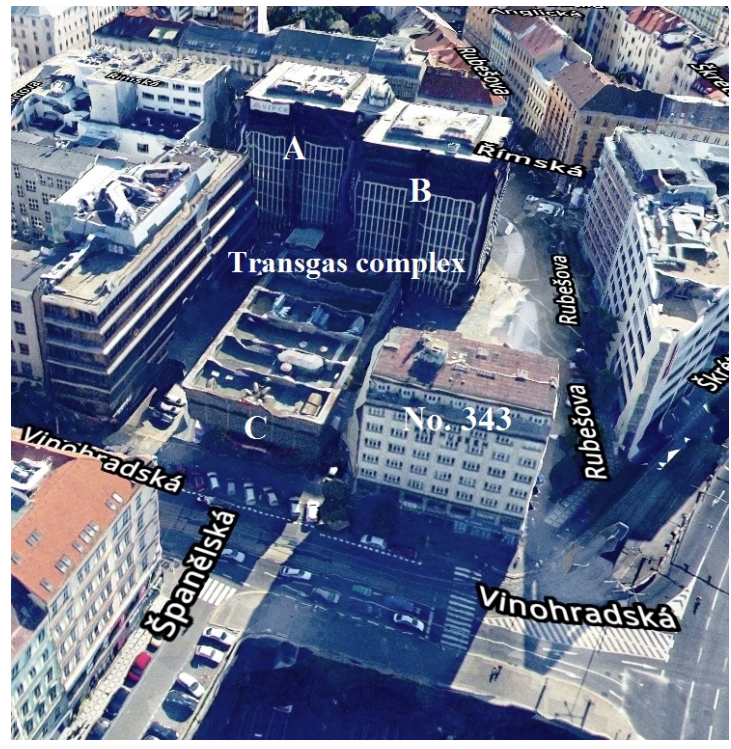

Figure 3. A view of the Transgas complex (www. google.com - modified).

\subsection{Characteristics of New Buildings}

The Vinohrady Administration Centre (hereinafter referred to as VAC - see Figure 4 was built in the vacated space and a relatively narrow building will be added to the existing building No. 343 "Nad Muzeem" ("Above the Museum") by its private owner (hereinafter referred to as AAM - see Figure 7).

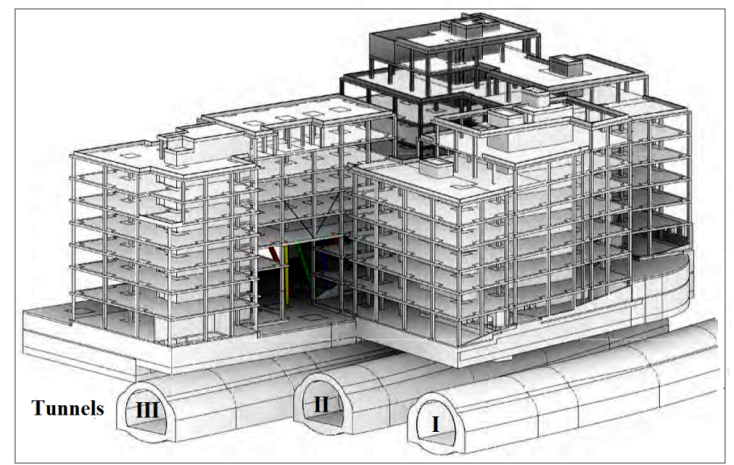

Figure 4. Vinohrady Administration Centre complex (2] - modified).

\subsection{The Nature of the Influence on Tunnels II AND III BY THE COMPleted Demolition AND THE NeW BuILdings}

A detailed condition survey of the lining of Tunnels II and III was carried out prior to the commencement of demolition work on the Transgas complex. No damage to the tunnels related to their previous loading was documented.

Relieving the loads acting on the lining of tunnels during demolition of buildings and excavation of construction pits, and these will also have an asymmetric character, will cause unusual deformations and the formation of cracks in the lining. These undesirable effects had to be analysed in detail by advanced structural analysis. 
The construction of new VAC and AAM buildings will logically have a significantly positive effect on the deformations originating during the demolition and excavation of the construction pits - as the deformations are significantly reduced and the cracks close. This condition was also analysed in detail by structural analysis.

During both fundamental phases of the current construction - the demolition of Transgas buildings, excavation of construction pits and construction of new VAC and AAM buildings - it is necessary to conduct geotechnical monitoring according to the approved design 3. Geotechnical monitoring, in addition to checking the results of static assessments, has great safety significance, as it allows for monitoring of real deformations of the operated tunnels. The administrator of the tunnels and all participants in the construction will undoubtedly have a special interest in assessing this integral part of the construction, as it is being carried out in close proximity to the tunnel structures, i.e. in the protection zone of the railway line.

\section{Assessment of the Influence of DEMOLITION AND BUILDINGS ON TUNNELS II AND III}

\subsection{Engineering Geological Conditions}

The engineering geological conditions in the area of the future construction of the new VAC and AAM buildings and the relevant section of the Vinohrady tunnels were described in detail on the basis of archival documents, nine new cored boreholes and the completed analyses in the Final Report of the EG Survey from 2018 4.

The Vinohrady tunnels are located in a rock environment throughout the whole area of interest. The rock environment was assessed by EG survey [4] in terms of faulting on the basis of the GSI index and all strength-related and deformational parameters of the rock types and superficial deposits encountered all required for a structural analysis of the Vinohrady tunnels to be affected by the future buildings were thus determined.

The Vinohrady tunnels were driven through the Prague Ordovician Libeň Formation. Both lithological facies of this formation, i.e. moderately to heavily weathered silty-clayey shale, strength classes R4 (5$15 \mathrm{MPa})$ and $\mathrm{R} 5$ (15-50MPa) and weathered to fresh quartzite, strength class R2 (50-150MPa), are evident. A substantial part of the rock environment in the area of interest of the new buildings is formed by a quartzite layer (see Figure 5 ) dipping at $45^{\circ}$ toward $\mathrm{SSE}$; shale is found in the peripheral parts of the construction site. Five geological profiles are processed in the exploratory report [5], of which the following one is presented here. This was essential for the assessment of Tunnels II and III due to the asymmetric load and the formation level of the new buildings located in close proximity to the external surface of the tunnel lining. This geological profile $1-1 \sqrt{1}$ (see Figure 6) is found under the facades of buildings adjacent to Vinohrady Avenue.

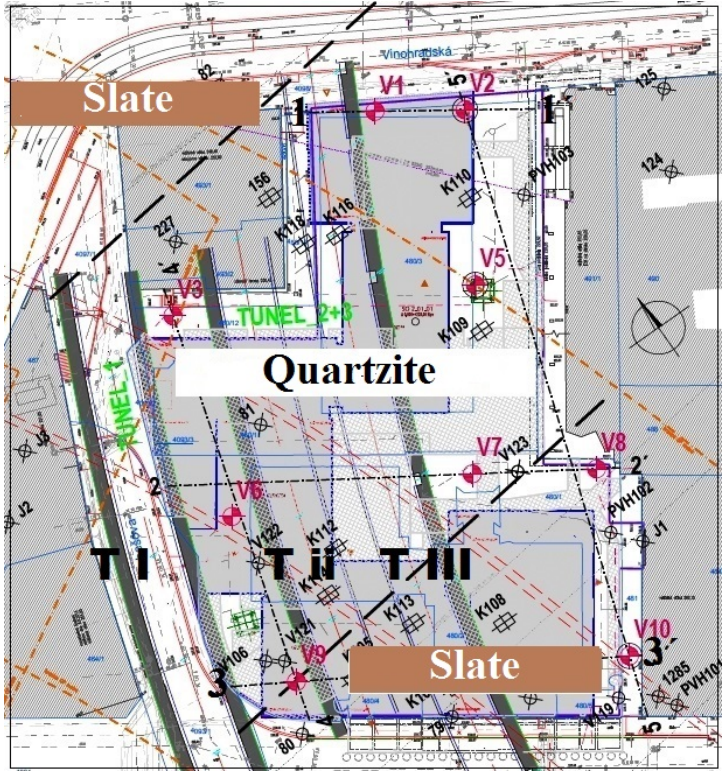

FiguRE 5. Distribution of rock types encountered in the area of interest $(4-$ - modified).

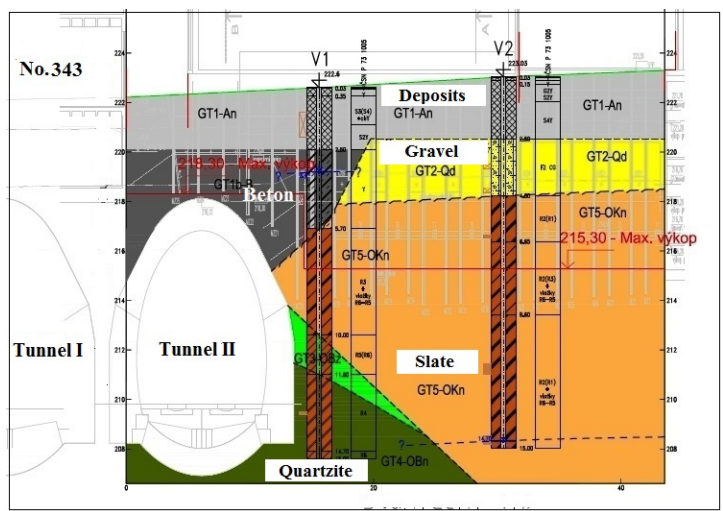

Figure 6. Geological profile $1-1$ ' $(4$ - modified $)$.

\subsection{Static Assessment of the Influence of New Buildings on Tunnels II AND III}

The static assessment was carried out repeatedly by various agencies [2, 5, 7. The following text describes the calculation [2], which was carried out by the finite element method using the program SOFISTIK 2D (planar solution), which models the lining of tunnels in interaction with the surrounding environment

\footnotetext{
${ }^{1}$ The foundation base level of the new buildings was additionally changed in the designs so that incursion of the bottom of the construction pits to the excavation of Tunnels II and III was prevented. The minimum distance from the external surface of the upper vault of Tunnels II and III was set at $0.75 \mathrm{~m}$ taking into consideration the magnitude of the overcut required for the external waterproofing.
} 
and identifies the places of possible cracking. The behaviour of soils was simulated using the Hardening-Soil non-linear elastic-plastic model. It takes into account the increase in soil stiffness after unloading (e.g. the condition after the excavation of the construction pit). The Drucker-Prager non-linear constitutive model was applied to the simulation of the behaviour of the tunnel lining. The model parameters were derived from the compressive strength of the homogenised stone masonry plus mortar material by means of conversion relations.

The calculations were carried out in exceptional detail for four chosen sections I', I" , II and III' (see Figure 7) selected to cover the construction progress and changes in the loads inducing asymmetric stresses on the tunnels. The conditions in the remaining sections I, II' and III are sufficiently represented by the calculations for the selected sections.

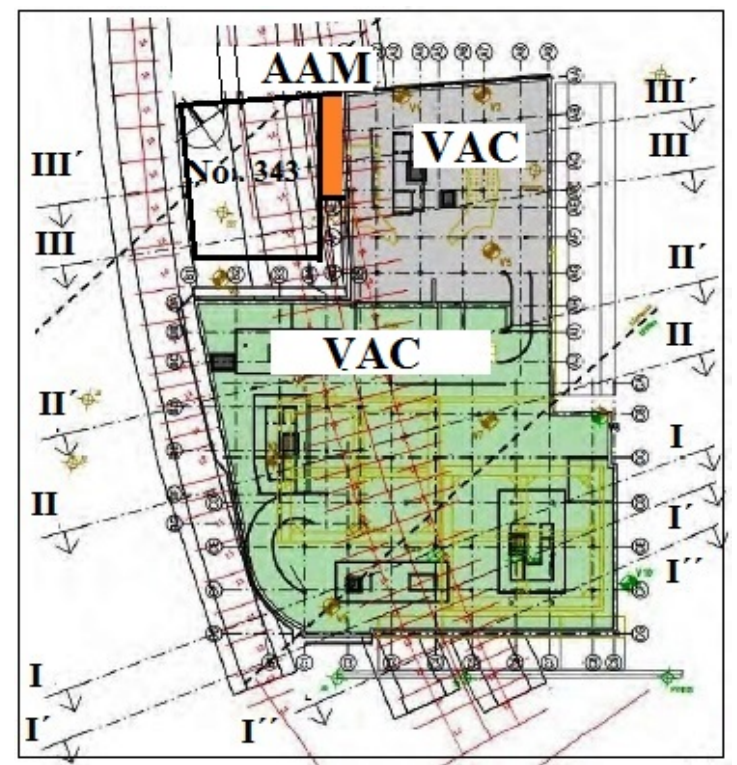

Figure 7. Cross-sections through the new VAC and AAM buildings ([2] - modified).

The calculations were divided into six construction phases and four sub-phases, namely the primary state of stress (phase 100), construction of the tunnels (phases 200 and 300), current condition (phase 400 - surcharging of tunnels by existing buildings), construction pit (phase 500 - demolition of Transgas buildings, excavation of soil from the construction pit, sub-phase 510 - characteristic loading; sub-phase 520 - design loading), new buildings (phase 600 - loading induced by the VAC and AAM buildings, sub-phase 610 - characteristic loading, sub-phase 620 - design loading). Phases 400 to 600 with the respective sub-phases are relevant for assessing the influence of existing buildings and new buildings on the Vinohrady tunnels.

The results of the calculations are graphically displayed in 22 for the calculation phases 400 to 600 and for all monitored sections I", I', II, III' in the form of principal stresses in the lining, radial loads acting on the lining, contact stress between the lining and rock, places of formation of tensile cracks in the lining - in all cases for both the characteristic and design loads. The deformations of the lining are documented only for standard loading.

The following text only presents the assessment of construction phases 500 and 600 (demolition, construction pit, new buildings) in section III', which were the most important for the assessment of Tunnels II and III, with respect to the effect of asymmetric loading acting on the Tunnel III and the fact that the foundation base of the new buildings is in close proximity to the external surface of the lining of Tunnel III.

PHASE 500: The diagram for the assessment in Phase 500 Demolition and Construction pit in section III' is presented in Figure 8 The excavation of the construction pit is considered only for the VAC building. Given the unfavourable asymmetric loading by the unexcavated construction pit for the AAM building, the calculation is made on the safe side.

In Phase 500, a more significant asymmetric stressing of the upper vault of Tunnel III with the maximum deformation of $4.1 \mathrm{~mm}$ occurs in the left part of the vault, whilst stressing of the Tunnel II is moderately asymmetric with a maximum deformation of $0.6 \mathrm{~mm}$ (see Figure 9 ).

Tensile stressing of Tunnel III (Figure 10 occurred on the external surface of the left part of the upper vault, and on the internal surface of the upper vault in its middle and in the right part. The width of cracks is around $0.1 \mathrm{~mm}$. Tensile damage occurs even on the internal surface of the left side wall. This, as well as the tensile damage in the footings of the side walls, can be considered of little significance in terms of the bearing capacity of the whole lining. Regarding Tunnel II, small tensile stressing is obvious in the middle of the internal surface of the upper vault and on the left external surface of the vault. The width of cracks is under $0.05 \mathrm{~mm}$. Even here, the damage to the footings of side walls can be assessed as insignificant.

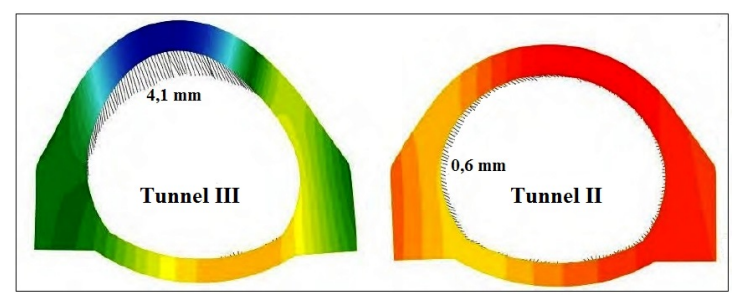

Figure 9. Deformation of Tunnels II and III in phase 500 (2]-modified). 


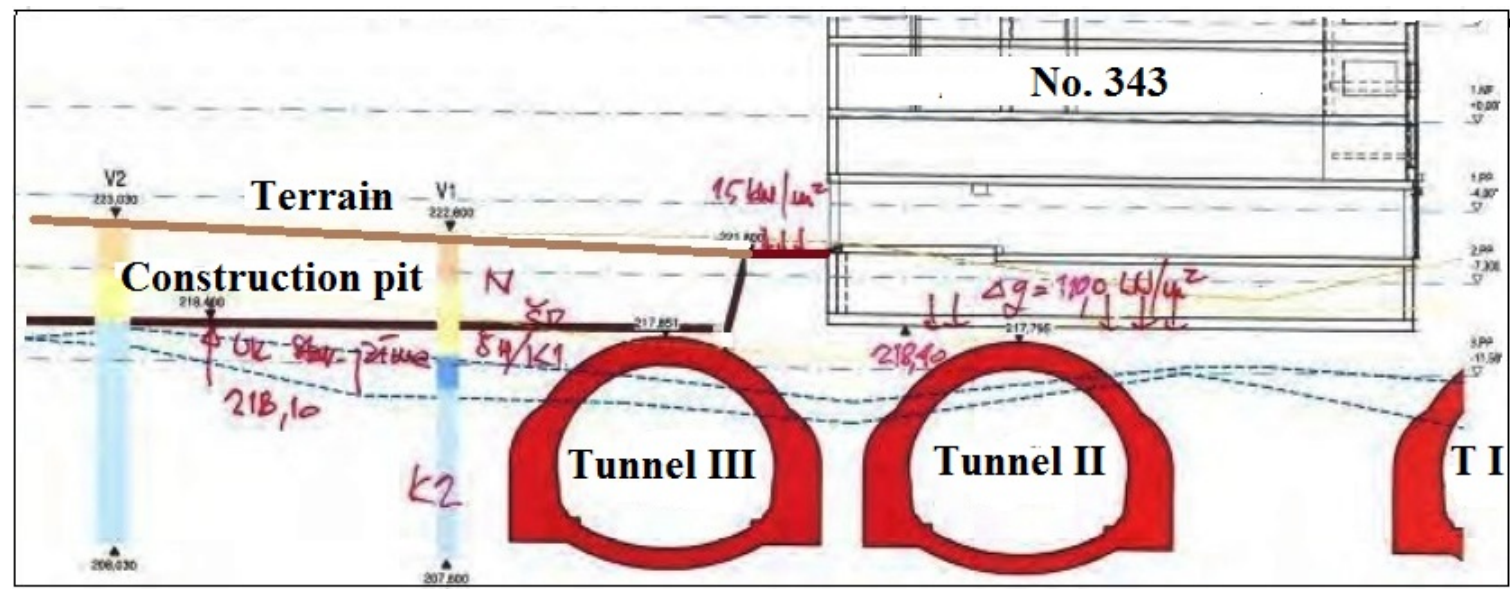

Figure 8. Construction phase 500 Demolition and Construction pit in section III' 2 .

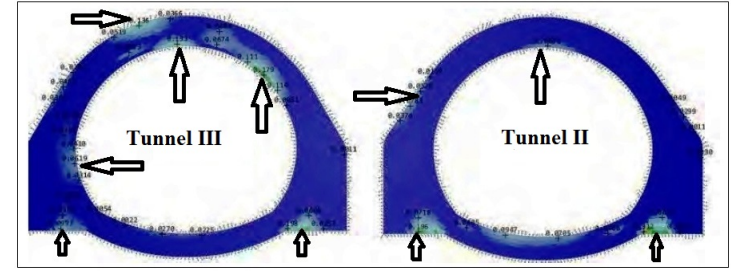

Figure 10. Tensile damage to Tunnels II and III by fissures in phase 500 ([2] - modified).

PHASE 600: The chart for assessing the new buildings in section III' in phase 600 for concurrent action of the VAC and AAM buildings is presented in Figure 11 .

Results of calculations in Phase 600, VAC and AAM buildings, showed that after surcharging by both new buildings, the asymmetric deformations are eliminated in the negatively affected areas of the vault cross-sections and the tensile stress changes to compressive stress, which then leads to the closing of cracks in the upper vaults of Tunnels II and III and also in the side walls and their footings.

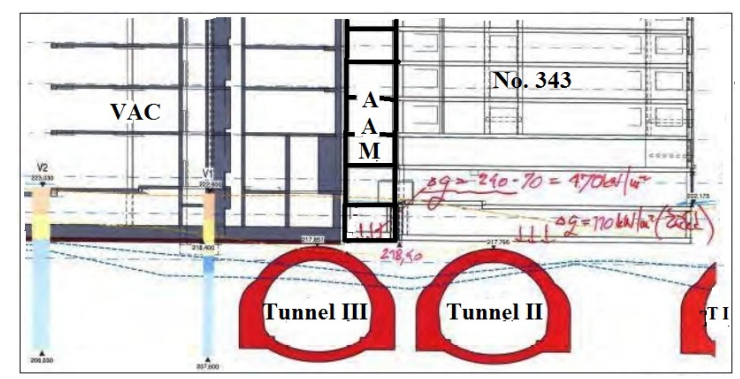

Figure 11. New construction in section III' - Phase 600 the VAC and AAM Buildings [2].

\section{ACKNOWLEDGEMENTS}

The demolition of the four Transgas buildings was carried out above the Vinohrady tunnels II and III in 2019, and without interrupting the railway services. The construction pits will be excavated and the construction of the new buildings of the Vinohrady Administrative Centre and the
Above the Museum addition will be also excavated with operations still running. The next phase of construction did not take place during 2020 or in the first quarter of 2021.

The completed static calculations [2,5-7] confirmed that the unfavourable effects of the demolition and excavation of construction pits are almost completely eliminated by loads induced by the new buildings, so that the static function and safety of tunnel linings are still maintained. The audit of static calculations 8 , ordered by the administrator of the tunnels, confirmed the results of the calculations with a requirement for modification of the design so that the foundation base of the new buildings is at least $0.75 \mathrm{~m}$ above the top of the external surface of the tunnel linings, where the overcut for the external asphalt waterproofing amounts to 40 to $50 \mathrm{~cm}$.

\section{REFERENCES}

[1] J. Sedláček. Expert description and assessment "Construction of the Vinohrady tunnels II and III in 1940/1945". Prepared for the Administration of the Prague Railway Junction, 02/1980.

[2] VIN Consult s.r.o. Vinohradská Administration Centre, Vinohradská Avenue No. 325/8, Prague 2. Assessment of influence of the new building on the structure of existing tunnels of Czech Railways, part of Statis Assessment. Prepared by VIN Constult s.r.o., 04/2019.

[3] FG Consult s.r.o. Vinohrady Administration Centre. Stabilisation of construction pit, cross-section part II. Prepared by FG Consult, s.r.o., 04/2019.

[4] SG Geotechnika a.s. Final report from the engineering geological survey for the Vinohradská Administration Centre in Prague 2. Prepared by SG Geotechnika a.s., $02 / 2018$.

[5] Červenka Consulting s.r.o. Vinohrady tunnels. Nonlinear assessment of bearing capacity of tunnel linings. Prepared by Červenka Consulting, s.r.o., 04/2019.

[6] SUDOP. Vinohradská Administration Centre, current condition survey of Vinohrady tunnels. Static assessment of the lining after the new construction. Prepared by SUDOP Praha, 08/2015. 
[7] Amberg Engineering Brno, a.s. Static assessment of the influence of the addition to the Above the Museum apartment building, Vinohradská Street No. 6, Prague 2. Prepared by Amberg Engineering Brno, a.s., 06/2018.

[8] J. Barták. Checking on static assessments and professional audit of the inluence of the construction of the Administration Centre and the addition of the Above the Museum building on the Vinohrady tunnels.

Prepared by Prof. Ing. Jiří Barták, DrSc., 09-11/2019. 